\title{
Effect of Pomegranate Seed Oil on Certain Food Spoilage Microorganisms and its Role in Shelf Life of Cream.
}

Hoida A. M. El-Shazly ${ }^{1}$; Enaam SH. A. Mohamed ${ }^{2}$ and Somia H . Abdelatif ${ }^{3}$

${ }^{1}$ Dairy Research Department, Food Technology Research Institute ، ARC

${ }^{2}$ Fats and oils Research Department Food Technology Research Institute ، ARC

${ }^{3}$ Horticultural Crops Processing Research Department, Food Technology Research Institute ، ARC

\begin{abstract}
This study aims to investigate the effect of pomegranate seed oil on the quality of cream during cold storage $\left(4^{\circ} \mathrm{C}\right)$. Cream was divided into four equal portions, the first portion with no additives served as a control. For the other three portions, $0.5,1.0$ and $1.5 \%$ of pomegranate seed oils were added individually to each portion of cream. The cream was then stored in refrigerator $\left(4^{\circ} \mathrm{C}\right)$ to 45 days. Results showed that the total soluble solids, fat and protein of sour cream increased with the increase of the added pomegranate seed oil, but the carbohydrate content was decreased. The results also reveal that the use of cream containing pomegranate seed oil (PSO) led to increase the peroxide value and refractive index during cold storage. This was more remarkable in cream containing pomegranate seed oil at the higher level of concentration $(1.5 \%)$. The same data showed that the peroxide values gradually increased, while iodine values showed gradual decrease during cold storage. The main fatty acid of pomegranate seed oil identified by GC was punicic acid ( $84.59 \%)$. The saturated fatty acids, mono-unsaturated acids and polyunsaturated fatty acids were $6.33,5.8$ and $87.87 \%$ respectively.Antimicrobial effect of different concentration of pomegranate seed oil were studied on four bacteria (E. coli, S. aureus , B. cereus and Salmonella typhimurium) and two fungi (Aspergillus niger and Candida albicans). Results indicated that the higher antimicrobial effect was detected against yeast and mold ( from 20-23 mm). Also, data showed that cream samples fortified with different concentration of pomegranate seed oil were free of libolytic bacteria and yeast \& mold, compared to control (fresh cream) till one month. Higher scores for organoleptic attributes were achieved for cream containing $0.5 \%$ pomegranate seed oil till 30 days . It could be seen that pomegranate seed oil can reduce the oxidative degradation of fatty substances as well as to inhibit the growth of spoilage microorganisms.
\end{abstract}

Keywords : Pomegranate seed oil, cream, chemical and physical properties, inhibiting microbial growth and organoleptic test .

\section{INTRODUCTION}

Huge amount of plant biomass wastes are released yearly as by-products from the agro-food industries . These wastes are of great importance as natural antioxidants. Recently, the seeds of pomegranate have considered as waste materials, because of their exclusive impact and valuable characteristics. The seeds of pomegranate constitute of about $20 \%$ of fruit's edible part. 10 to $20 \%$ (of total seed weight) oil are usually found in pomegranate ((Mehta and Lansky,( 2004)\& Sassano et al., (2009) .

Low oil content which are rich in polyunsaturated fatty acids found in pomegranate seeds . Pomegranate seeds oil contains conjugated linolenic acid isomer punicic $\operatorname{acid}(70 \%$ of the total fatty acids), which characterized with metabolic syndrome and inflammation activities. High amount of antioxidants are also present in the seeds oil. Punicic of about $31.8-86.6 \%$ was found in the seeds oil, followed by linoleic acid $(0.7-24.4 \%)$, oleic acid (0.4-17.4\%). strearic acid (2.8-16.7\%) and palmitic acid (0.3-9.9\%)(Sassano et al., (2009), Amit et al, (2010) and Habibnia et al., (2012). .

Antioxidants are of significant role in retarding lipid oxidation in foods, due to their off-flavors and undesirable oxidized chemical compounds. A number of natural antioxidants have been found to elongate the shelf life and oxidative stability of stored products (Saad et al., 2007 and Jang et al., (2012).

High antioxidant activity of the extracts from different part of pomegranate fruit, such as peel, juice and seeds were detected, and the antioxidant activity has been attributed to the high level of phenolic compounds. (Noda et al . (2002) and Singh et al. (2008)

Antimicrobial compounds and their effets against pathogenic bacteria has been established for long time ago. Natural antimicrobials are of better alternatives to synthetic antimicrobial compounds. These are derived either from animals, plants or other microorganism. The use of these natural antimicrobial such as organic acids, essential oils, plant extracts, and bacteriocins could be considered as good alternatives to ensure food safety (Smith-Palmer et al.(2001), Raybaudi et al.,(2008), Emir Coban and Qzpolat,(2013).

The aim of the present study is to prepare cream with different concentrations of pomegranate seed oil to improve its value and to prolong the self life.

\section{MATERIALS AND METHODS}

Fresh Pomegranate (Punica granatum L.) seeds were obtained were obtained from the local market in Giza region, Cairo, Egypt. Fresh buffalo's milk (5.5\% fat) was obtained from the processing plant of Food Technology Research Institute .

For the preparation of pomegranate seeds powder, the obtained pomegranate seeds were moisture content reached $5-6 \%$. The dried seeds were ground in a laboratory disc mill. Ground seeds were sieved into mean particle size distribution of less than 40-mesh

Raw cream was standardized to $45 \%$ fat and $9.5 \%$ not fat-solids, pasteurized at $74^{\circ} \mathrm{C}$ for $10 \mathrm{~min}$. Cream divided into four equal parts, the first part with no additives served as control, 5, 1.0 and $1.5 \%$ of oil extract were added the other three portions. Then the treated cream was stored in refrigerator $\left(4^{\circ} \mathrm{C}\right)$, and analyzed when fresh and after 15 and 30 days of storage.

For extracting the pomegranate seeds, dried ground and sieved (50 g) were extracted in a Soxhlet extraction system using hexane. The extraction was carried out for four hours. The crude oil extracts obtained were kept at $4^{\circ} \mathrm{C}$ until further use 
Table 1. Oil contentof pomegranate seed sample.

\begin{tabular}{lc}
\hline Properties & values \\
\hline Weight of grounded seeds (g) & 50.04 \\
Weight of oil obtained (g) & 8.1 \\
Percentage of oil obtained from sample & $16.2 \%$ \\
\hline
\end{tabular}

Total solids contents ( total protein, fat and ash ) of cream were determined according to the methods described by A.O.A.C (1994). Refractive index (RI) of oils was determined at $25{ }^{\circ} \mathrm{C}$ according to A.O.A.C , (2000) by using refractometer (NXRL-3Poland). Free fatty acids (FFA) and peroxide value(Meq.O2/Kg oil) were determined according to the methods of the A.OA.C. (2000). Iodine and saponification values of pomegranate seeds oils were calculated from fatty acids percentage by equation according to Susana Nelson (1995). The fatty acids methyl esters were prepared using trans esterification with cold methanolic solution of potassium hydroxide. The fatty acids methyl esters were identified by Gc - capillary column according to the methods of IOOC (2001).

Antimicrobial activity of different level of pomegranate oil was carried out using four pathogenic bacterial strains and two pathogenic fungal strains. Disc diffusion method (Kotzekidou et al., 2008) was used for detected the antimicrobial effect. The bacterial strains used in this method (Gram positive and Gram negative) were kindly supplied by the Department of Microbiology, Faculty of Agriculture Cairo University. These strains were ATCC 25923, Eschrichia coli, ATCC, Staphylooccus aureus 25922, Bacillus cereus ATCC 33018, Salmonella typhimurium, ATCC 20231. The bacterial cultures were maintained on nutrient agar slants at $4{ }^{\circ} \mathrm{C}$ and sub cultured on nutrient broth at $37^{\circ} \mathrm{C}$ for 24 hours prior to incubation . Food-borne filamentous fungus Aspergillus niger VanTieghem was isolated from different spoilage sources vegetables, fruits, grains (Rizk et al ., 2009).

Candida albicans CAIM -22 was obtained from EMCC (Egyptian Microbial Culture Collection) Ain Shams University, Cairo, Egypt.

Total viable bacterial counts were enumerated on standard plate count agar (Marth, 1978). Mould and yeast, libolytic and proteolytic bacterial counts were determined according to APHA (1994).

Cream samples were scored for organoleptic properties by a regular tests panel from 20 staff members of dairy department in Food Technical Research Institute. Cream samples were evaluated for sensory attributes according to Keating and White (1990), using a scheme of 15 points for appearance, 10 points for acidity, 30 points for body and texture and 45points for flavor.

Coliforms were enumerated according to Harrigan and McCance (1996) using Violt Red agar medium.

Staphylococcus aures was determined according to American public health Association methods (APHA, 1994).

\section{RESULTS AND DISCUSSION}

Chemical composition of fresh cream with or without the addition of pomegranate seed oil are given in Table (2). From these results it could be observed that the addition of pomegranate seed oil (PSO) to cream led to increase the total solids contents compared with the control. The results are in agreement with those reported by Essaway(2007). On the other hand, the carbohydrate content decreased as the level of added pomegranate seed oil increased.

Table 2. Chemical composition of fresh cream with and without the addition of pomegranate seed oil :

\begin{tabular}{lcccc}
\hline \multirow{2}{*}{ Gross composition\% } & \multirow{2}{*}{ Control } & \multicolumn{3}{c}{ Oil concentration \% } \\
\cline { 3 - 5 } & & $\mathbf{0 . 5}$ & $\mathbf{1 . 0}$ & $\mathbf{1 . 5}$ \\
\hline Fat & 45 & 45.5 & 46 & 46.5 \\
Protein & 2.281 & 2.315 & 2.301 & 2.421 \\
Ash & 0.092 & 0.221 & 0.302 & 0.231 \\
Carbohydrate & 2.627 & 2.464 & 2,397 & 2.348 \\
Total solids & 50 & 50.5 & 51 & 51.5 \\
\hline
\end{tabular}

The physical and chemical properties of pomegranate seeds oil was determined and the obtained data was recorded as in Table (3). The examined pomegranate seeds powder contained the crude oil at level of $16.2 \%$ from its dry weight as illustrated in Table (1). The data presented in Table (3) revealed that the acidity of $0.45 \%$, peroxide value of $7.75 \mathrm{meq} \mathrm{O}_{2} / \mathrm{kg}$ oil, refractive index of 1.51872, saponification value of 194.21, and iodine value of 237.11 were detected. These high values of IV are due to the high level of polyunsaturated fatty acids (punicic acid) in pomegranate seed oil. Also the fatty acids composition of oil extracted from dried pomegranate seeds were studied. Nine fatty acids were identified in the variety under this study.

Table 3. Physical and chemical properties of pomegranate fruit seed oil :

\begin{tabular}{lc}
\hline $\begin{array}{l}\text { Characteristic of pomegranate seed } \\
\text { oil }\end{array}$ & Values \\
\hline Acidity \% & 0.45 \\
Peroxide value (meq $\mathrm{O}_{2} / \mathrm{kg}$ oil) & 7.75 \\
Refractive index $\left(\right.$ at $\left.25^{\circ} \mathrm{C}\right)$ & 1.5187 \\
Saponification value $(\mathrm{mg} \mathrm{KOH} / \mathrm{g}$ oil) & 194.21 \\
Iodine value $\left(\mathrm{I}_{2} / 100 \mathrm{~g}\right.$ oil $)$ & 237.11 \\
\hline
\end{tabular}

Fatty acids composition:-

Fatty acids content $(\%)$

Saturated fatty acid

Palmitic acid 0.99

Stearic acid $\quad 1.21$

Arachidic acid $\quad 0.20$

Behenic acid $\quad 3.93$

Total saturated fatty acids $\quad 6.33$

Mono-unsaturated fatty acids
Oleic acid

acid Gadoleic $\quad 1.05$

$\begin{array}{ll}\text { Erucic acid } & 1.63\end{array}$

Total mono unsaturated fatty acids $\quad 5.8$

Poly-unsaturated fatty acid

Punicic acid $\quad 84.59$

Linoleic acid $\quad 3.28$

\begin{tabular}{lc} 
Total polyunsaturated fatty acids & 3.28 \\
\hline
\end{tabular}

From the obtained results in this Table, it could be observed that the sum of saturated fatty acids , monounsaturated fatty acids and polyunsaturated fatty acids percentage in pomegranate seeds oil (PSO) were 6.33 , 5.8 and $87.87 \%$, respectively. Therefore, the percentage of the total saturated fatty acids in the pomegranate seed oil was very low $(6.33 \%)$ that explained the beneficial effect for the health and nutrition by incorporating of the pomegranate seed oil into food technology and human nutrition. Results of this study indicate that the main 
saturated fatty acids were behenic acid (3.93\%) and stearic acid (1.21\%), mono unsaturated fatty acids was oleic acid $(3.12 \%)$, gadoleic $(1.05 \%)$ and erucic $(1.63 \%)$. The predominate polyunsaturated fatty acid in the extracted oil of studied variety was punicic acid $(84.59 \%)$ followed by linoleic acid (3.28). These results are agreement with Habibnia et al. (2012)who reported that the oil extracted from pomegranate seed contains a high concentration of punicic acid.

\section{Effect of pomegranate seed oil on shelf life of raw cream:}

A . Effect of pomegranate seed oil on reducing lipid oxidation

Lipid oxidation is one of the main limiting factors for the quality and acceptability of milk and milk products, The changes in iodine value (IV), Peroxide value (PV), saponification value (SV), refractive index (RI) and free fatty acids (FFA) of cream containing different concentrations of pomegranate seed oil were taken as indices for oxidation stability during storage period (45days) in refrigerator $\left(4^{\circ} \mathrm{C}\right)$ were estimated. The peroxide value of oil is a valuable index to determined oil quality (Saeed et al., 2013). The chemical properties of oil peroxide and iodine value demonstrated that the unsaturation and potential oxidative sensitives of the oil (Moodley et al ., 2007) .

Free fatty acids (FFA) are responsible for rancidity and off flavors in fatty food materials. Production of free fatty acids and their increase in foods could be used to monitor the extent of spoilage (Rahman et al., 2009).

Changes in the FFA values of cream samples were showed in Table (4). A decrease in FAA value was observed in cream samples containing pomegranate seeds oil at different concentrations, compared with the control samples during cold storage for 15 and 30 days. The ratio of decrease in (FFA) in cream samples containing pomegranate seeds oil at concentration $0.5,1.0$ and 1.5\% during storage for 15 days were $-14.94,-25.62$ and $33.45 \%$ respectively and after 30 days were $-28.2,39.98$ and $-50.16 \%$, respectively. It could also be observed that as the type of phenolic compounds used, and due to the inhibitory effect of these compounds to molds on lypolytic bacteria. These observation are in agreement with those of Al .Otaibi and El.Demerdash,(2008), who reported that the total volatile fatty acids of lebaneh were affected by the type of essential oil .

The data in Table (4) demonstrate that the addition of pomegranate seeds oil led to an increase in PV of cream mixed with pomegranate seed oil, compared with PV of control, but it was more remarkable in cream containing higher level of addition (1.5\%) of pomegranate seed oil. Commonly, PV increased continuously in all cream samples during storage periods. The rate of increase in the value was decreased with increasing of pomegranate seeds oil concentration from $0.5 \%$ to $1.5 \%$, during storage for 45 days. If the PV becomes higher than 9 meq / $1000 \mathrm{~g}$ oil, it indicates oxidative corruption in oil (Saeed et al., 2013). The amount of PV for studied samples is in range of $\left(1.40\right.$ to 7.29 meq $\left.\mathrm{O}_{2} / 1000 \mathrm{~g}\right)$. The results show that sharp decrease in PV and increase in FFA may due to growth of mold in the top of all samples with and without addition of pomegranate seed oil during cold storage for
45 days. While refractive index used as physical parameter to evaluate purity and quality of essential oil. From the results (Table 3), it is clear that, pomegranate seed oils have higher refractive index (1.5187) than other plant oils. So, it is characteristic specification the pomegranate seed oil. Data in Table (4) indicted that the refractive index of cream samples increased continuously during storage periods, and also increased with increasing of pomegranate seed oil concentrations.

Also, the same data appeared that the values of iodine value are nearly the same at zero time for all samples. But it increased in control sample, compared with the cream containing of pomegranate seed oil at different level during cold storage for 15 and 30 days, vice versa during cold storage for 45 days.

Table 4. Chemical and physical properties of cream with and without pomegranate oil:

\begin{tabular}{lccccc}
\hline \multirow{2}{*}{ Properties } & Storage & Contr & \multicolumn{3}{c}{ Oil concentration \% } \\
\cline { 4 - 6 } & period (days) & ol & 0.5 & $\mathbf{1 . 0}$ & $\mathbf{1 . 5}$ \\
\hline \multirow{3}{*}{ Acidity \% } & Fresh & 0.119 & 0.118 & 0.116 & 0.114 \\
(FFA) & 15 & 0.281 & 0.239 & 0.209 & 0.187 \\
& 30 & 0.638 & 0.458 & 0.383 & 0.318 \\
& 45 & 3.24 & 4.57 & 5.54 & 7.07 \\
Peroxide & Fresh & 1.40 & 1.42 & 1.94 & 2.63 \\
value (meq & 15 & 2.43 & 3.70 & 4.30 & 4.96 \\
$\mathrm{O}_{2} /$ kg oil) & 30 & 3.29 & 4.89 & 6.47 & 7.29 \\
& 45 & 1.47 & 1.51 & 1.56 & 1.65 \\
Refractive & Fresh & 1.4594 & 1.4596 & 1.4596 & 1.4607 \\
index (at & 15 & 1.4595 & 1.4597 & 1.4599 & 1.4613 \\
25 & 30 & 1.4596 & 1.4602 & 1.4607 & 1.4614 \\
& 45 & 1.4597 & 1.4601 & 1.4607 & 1.4615 \\
Saponification & Fresh & 199.99 & 198.2 & 196.89 & 196.18 \\
value (mg & 15 & 199.11 & 198.79 & 198.10 & 195.55 \\
KOH/g oil) & 30 & 201.16 & 198.73 & 199.94 & 196.96 \\
& 45 & 198.1 & 198.12 & 200.53 & 199.55 \\
Iodine value & 15 & 27.50 & 27.05 & 26.87 & 26.79 \\
$\left(\mathrm{I}_{2} / 100 g\right.$ oil) & 30 & 28.54 & 27.80 & 28.27 & 28.10 \\
& 45 & 24.54 & 25.63 & 26.69 & 26.22 \\
\hline
\end{tabular}

Data presented in Table (4) show that at the beginning of storage and during cold storage for 15 and 30 days the saponification values of cream containing different concentrations of pomegranate seeds oil were lower than in control cream sample. Regarding to oxidative stability, data given in Table (4) showed that free fatty acids, peroxide value, refractive index, iodine value and saponification value of cream were different between different treatments and control from the beginning of cold storage and during the subsequent cold storage. This observation was more remarkable containing pomegranate seeds oil at the higher level of concentration. These results could be attributed to the fatty acid composition of pomegranate seed oils. Increase of the level of unsaturated fatty acids in the fat, accelerates the oxidative changes. Also, the data from the same Table indicated that at the beginning of storage the FFA and iodine value of different treatments and control cream samples were nearly.

The results obtained in this study reflected the impact of pomegranate seed oil, as natural antioxidants in retarding of cream oxidation. The order of efficiency in inhibiting oxidation was in order $0.5,1.0$ and $1.5 \%$ pomegranate seed oil. This fact indicated that 
antioxidant activities of pomegranate seed oil were attributed to the presence of phenolic compounds specially ortho-diphenols (saeed et al., 2013).

\section{B. Antimicrobial effect of pomegranate seed oil:}

The antimicrobial activity of pomegranate seed oil was evaluated against foodborne pathogens that were Staphylococcus . aures ، E. coli Salmonella typhimurium ، B. cereus ' yeast and mold using the disk diffusion assay (Figure 1 ). The Figure (1) has demonstrated that the pomegranate seed oil (PSO) have antimicrobial properties against the tested organisms. This was shown by the production of zones of inhibition. Results indicated that the highest antimicrobial effect was found against yeast and mold, followed by Staphylococcus. aures and E. coli, and the lowest effect against was against Salmonella typhimurium and B. cereus. These results agree with (Rodriguez et al.,2010), who reported that the phenolic compound effect on microbial growth according to their constitution and concentration .

Results in the same Figure showed also that this inhibition responses varied among of concentrations of oil. Which, the activity of the seed oil against the test organisms reduced with decrease in concentration of the essential oil. This is in line with the work carried out by Ultee et al., (2002). Who mentioned that the antimicrobial activities of essential oil may be related to the concentration of the bioactive compounds present with gradually decreased with each successive dilution. The inhibitory activity of pomegranate seeds oil against the tested organisms ranged from 1 to $23 \mathrm{~mm}$. The best inhibitory effect of the pomegranate seeds oil was observed against Aspergillus niger ، Candida albicans (20 and $23 \mathrm{~mm})$ respectively ، Staph .Aureus (19 $\mathrm{mm})$ and E.coli $(18 \mathrm{~mm})$. Whoever, the pomegranate seed oil was found inactive against Salmonella typhimurium and B. cereus.The resistance capability of these bacteria against the pomegranate oil could be attributed to their cell wall or outward membrane structure, which has been reported to restrict the penetration of the plant oil ( Hayek and Ibrahim , 2012). and confirmed that phenolic were the most important compound active against bacteria (Hayek and Ibrahim , 2012). They also, identified galic acid as the most active compound for inhibition of bacteria. Therefore 'Baydar et al. (2004) indicated that the using of grape and pomegranate extracts may be exploitable as antimicrobial agents to prevent the spoilage of stored dairy products by bacteria.

Besides that, the results shows that gram positive bacteria are generally more sensitive to the pomegranate oil than negative bacteria. Commonly, gram-positive bacteria are more resistance to plant oil it has hydrophilic wall (Shan et al.,2007).

Scores of sensory evaluation for cream containing the pomegranate seed oil (PSO) at the levels of $0.5,1.0$ and $1.5 \%$ during cold storage ( zero time ,15, 30 and 45 days ) were presented in Table (5).

The data in this table reveal that ,the control cream gained the highest score either when fresh or throughout the intervals storage periods. Also, the data in Table (5) indicated that cream containing $0.5 \%$ pomegranate seed oil the most acceptable and was not different from the control. While the addition level over $0.5 \%$ PSO resulted in a product with slightly darker color and the body became softer and smoother. However, scores decreased slightly in all treatments as storage period advanced .

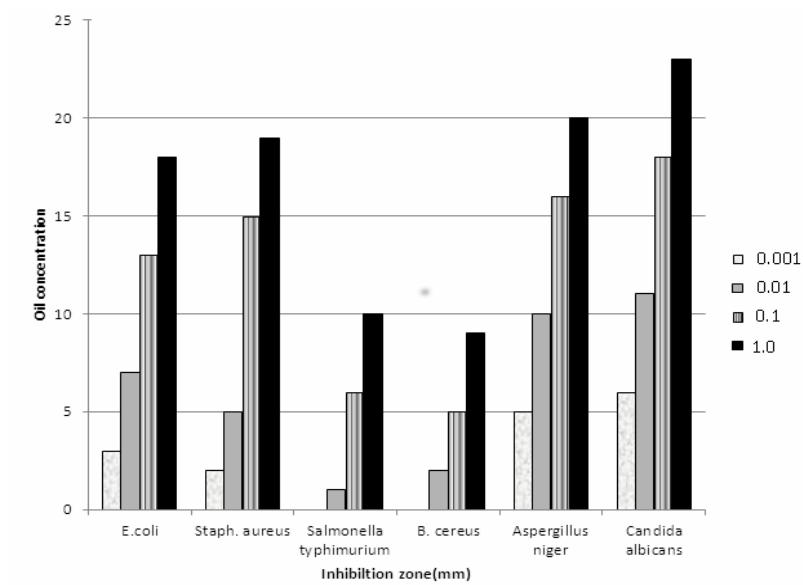

Fig. 1. Antimicrobial activity of different pomegranate oil concentration against different pathogenic microbial strains.

Table 5. Effect of addition of different levels of oil on organoleptic properties of cream during storage at refrigerator

\begin{tabular}{lccccc}
\hline Properties & $\begin{array}{c}\text { Storage } \\
\text { period (days) }\end{array}$ & Control & \multicolumn{4}{c}{ Oil concentration \% } \\
\cline { 3 - 6 } Flavor (45) & Fresh & 44 & 43 & $\mathbf{1 . 0}$ & $\mathbf{1 . 5}$ \\
\hline \multirow{3}{*}{ Body and } & 15 & 44 & 42 & 41 & 41 \\
Texture (30) & 30 & 40 & 41 & 40 & 38 \\
& Fresh & 30 & 30 & 28 & 27 \\
Acidity (10) & 15 & 30 & 29 & 27 & 27 \\
& 30 & 29 & 29 & 27 & 26 \\
& Fresh & 10 & 10 & 9 & 8 \\
Appear (15) & 15 & 10 & 9 & 8 & 7 \\
& 30 & 9 & 8 & 7 & 6 \\
& Fresh & 15 & 15 & 15 & 13 \\
Total & 15 & 15 & 14 & 13 & 12 \\
& 30 & 15 & 14 & 13 & 11 \\
& Fresh & 99 & 98 & 94 & 89 \\
& 15 & 99 & 94 & 89 & 85 \\
& 30 & 93 & 92 & 87 & 81 \\
\hline
\end{tabular}

It could be concluded that $\mathrm{s}$ it is possible to make a good quality cream by adding pomegranate seed oil till to $0.5 \%$ to improve and prolong the shelf life till one month.

Changes in microflora of cream affected by different concentrations of pomegranate seed oil addition $(0.5 \%, 1.0 \%$ and $1.5 \%)$ during cold storage period $\left(4^{0} \mathrm{C}\right)$ to 45 days were shown in Table (6). Total microbial count (TBC), yeast and mold, proteolytic bacteria and libolytic bacteria of cream samples was determined at the day of production (zero time), 15, 30 and 45 days of cold storage.

From Table (6), it could be observed that all cream samples contained with different concentrations of pomegranate seeds oil showed that counts of total bacteria of treatments with pomegranate seeds oil had lower count compared to control when fresh and throughout the storage period. The total bacterial count , lipolytic and proteolytic bacteria and yeast and mould increased slowly to the end of the storage period but all samples free yeast and mould, lipolytic and proteolytic bacteria till one month when coliform bacteria and Staphylococcus aureus absent in all treatments. This 
may be due to hygienic condition during the preparation and storage period beside the antimicrobial effect of pomegranate seed oil. These results are in agreement with Wenijao et al. (2014), who reported that the tea polyphenols inhibited the spoilage bacteria growth and extended the storage life of sausage samples stored at $20^{\circ}$ C. Smith - Palmer et al. (2001) concluded that plant essential oils could be used as natural antimicrobial agents in dairy products. With this all results, it was determined that pomegranate seed oil addition improved the microbiological quality and increased the shelf life of fresh cream. These observation are in agreement with Emir Coban et al. (2013) who reported that the use of natural antimicrobials such as organic acids, essential oils, plant extracts and bacteriocins could be good alternatives to ensure food safety .

Table 6. Microbiology analysis of cream as effected by of different levels of oil during storage period:

\begin{tabular}{lccccc}
\hline Properties & $\begin{array}{c}\text { Storage } \\
\text { period (days) }\end{array}$ & Control & \multicolumn{3}{c}{ Oil concentration \% } \\
$\mathbf{0 . 5}$ & $\mathbf{1 . 0}$ & $\mathbf{1 . 5}$ \\
\hline Total count & Fresh & $16 \times 10^{1}$ & $15 \times 10^{1}$ & $13 \times 10^{1}$ & $3 \times 10^{1}$ \\
(C.F.U./gm) & 15 & $7 \times 10^{2}$ & $23 \times 10^{1}$ & $18 \times 10^{1}$ & $8 \times 10^{1}$ \\
& 30 & $11 \times 10^{2}$ & $25 \times 10^{1}$ & $23 \times 10^{1}$ & $5 \times 10^{1}$ \\
& 45 & $16 \times 10^{6}$ & $12 \times 10^{6}$ & $15 \times 10^{5}$ & $9 \times 10^{5}$ \\
proteolytic & Fresh & N.D & N.D & N.D & N.D \\
bacteria & 15 & N.D & N.D & N.D & N.D \\
& 30 & N.D & N.D & N.D & N.D \\
& 45 & $8 \times 10^{2}$ & $5 \times 10^{2}$ & $7 \times 10^{1}$ & $6 \times 10^{1}$ \\
lipolytic & Fresh & $6 \times 10^{1}$ & N.D & N.D & N.D \\
bacteria & 15 & $7 \times 10^{1}$ & N.D & N.D & N.D \\
& 30 & $9 \times 10^{1}$ & N.D & N.D & N.D \\
& 45 & $6 \times 10^{3}$ & $5 \times 10^{3}$ & $9 \times 10^{2}$ & $4 \times 10^{2}$ \\
Yeast \& & Fresh & $1 \times 10^{1}$ & N.D & N.D & N.D \\
Mould & 15 & $2 \times 10^{1}$ & N.D & N.D & N.D \\
& 30 & $5 \times 10^{1}$ & N.D & N.D & N.D \\
& 45 & $9 \times 10^{4}$ & $6 \times 10^{4}$ & $8 \times 10^{3}$ & $5 \times 10^{3}$ \\
\hline
\end{tabular}

\section{CONCLUSION}

This results from this study showed that the use of pomegranate seed oil (PSO) is advantageous because of its antioxidant and antimicrobial properties . Owing to these properties pomegranate seed oil can reduce the oxidative degradation of fatty substances as well as inhibit the growth of spoilage microorganisms. In addition pomegranate seed oil is non -toxic and safe for public health, so it can be an acceptable alternative to chemical preservation.

Anyway, it is important that the methods and materials used for to lengthen the shelf- life of food are simple ، inexpensive and safe. For example pomegranate seed oil was extracted from pomegranate seed plant which considered as waste inexpensive and safe, beside its extraction method is simple.

\section{REFERENCES}

Al. Otaibi M. and El. Demerdash H. (2008) : Improvement of the quality and shelf of concentrated yoghurt (labneh) by the addition of some essential oils . Ari .J. Microbial. Res., 2:156161.
Amit p. ; Nidhi S. and Poon S. (2010 ): Lipid contents and fatty acids composition of seed oil from twenty five pomegranates varieties grown in India . Advanced J. Food SCI. Technol. 2: 12-15.

APHA, (1994): American Public Health Association ; Standard methods for the examination of dairy products , $16^{\text {th }} \mathrm{Ed}$, Washington. UAS .

A.O.A.C. (2000): Official Methods of Analysis $20^{\text {th }}$ Ed. Association of the Official Analytical Chemists Washington D.C., USA.

Baydar NG ; Ozcan H. and Sagdic O. (2004): Total phenolic contents and ntibacterial activities of grap (Vitis vinifera L) extracts . Food control, $15: 335-339$.

Emir Coban O. and Ozpolat E. (2013): The effects of different concentrations of rosemary (Rosmarrinus officinalis) extract on the shelf life of hot-smoked and vaccum -packed Luciobarbus esocinus fillets .J. Food Proc. And Pres., 37 (3), 269-374.

Essaway E. A. (2007): Effect of Hony Bee propolis on the keeping of Labenh made from buffalo's milk .J. Agric. Sci. Mansoura Univ . 23 (7) : 54455454.

Habibnia M. ; Ghavami M.; Ansaripour M. and Vosough S. (2012): Chemical evaluation of oils extracted fro five different varieties of Iranian pomegranate seeds. J. Food Bioscience Tech. 2 : $35-40$.

Hayek S.A. and Ibrahim S.A. (2012): Antimicrobial activity of Xoconostle pears (Opuntiamatudae) against Escherichia coli O157: H7in laboratory medium . International J. Microbiology, 1-6 doi :1 $0.15 / 2012 / 3684722$.

Harrigan W. F. and McCance M. E. (1996): Laboratory Methods in Microbiology. Academic Press, London \& New York, 292-293.

IOOC.(2001): Method of Analysis of the International Olive Oil Council Preparation of the fatty acid methyl esters from olive oil and olive pomace oil CO/T.20/DOC.No.24.

Jang H.A.; Kim Y.P. and Kim H.S. (2012): Effect of natural antioxidants on the oxidation of microencapsulated seed oil. Food Control 23, 528-534.

Keating, K and white, C. H (1990): Effect of ternative sweeteners in plain and fruit flavour yoghurt. J. Dairy Sci., 73:54.

Kotzekidou P. ; Giannakidis P. and Boulamatsis A. (2008): Antimicrobial activity of some plant extracts and essential oil against food borne pathogens in chocolate, Swiss Soc .Food Sci. Technol., 41,119-127

Marth E. H. (1978): Standard methods for examination of dairy products ${ }^{14} \mathrm{ed}$, Am .Pul .Health Sssoc, . Washington D.C.

Mehta R. and Lansky E. (2004): Breast cancer chemopreventive properties of pomegranate (Punica granatum) fruit extracts in a mouse mammary organ culture ، Eur. J. Cancer Prev. , 13,345 . 
Moodley R .; Kindess A .; Jonnalagadda s.b (2007): Elemental composition and chemical characteristics of five edible nuts (almond ، Brazil , pecan , macadamia and walnut) consumed in Southern Africa . J .Environment Science and Health, Part B, 42: 585-591.

Noda Y .; Janeyuki T.; Mori A. and Packer L. (2002): Antioxidant activities of Pomegranate fruit extracts and its anthocyanidns : delphinidin 'cyaniding and Pelargonidin . J. Agric. and Food Chemistry, 50: 166-171

Rahman IEA ; Dirar H. A. and Osman M.A. (2009): Microbiological and biochemical changes and sensory evaluation of camel milk fermented by selected bacterial starter cultures. Afr. J. Food Sci .3 (12) : 398-405.

Raybaudi-Massilia R.M.; Mosqueda-Melgar J. and Martin-Belloso O. (2008): Edible alginate-based coating as carrier of antimicrobials to improve shelf-life and safety of fresh-cut melon. Int .J. Food Microbio. : 121: 313-327.

Rizk M .A ; Khalil M.S. ; Abu-Zaid A and Magdi M.(2009): Evaluation of antimicrobial activity of stored fermented soybean products .Bull. Fac. Sci ‘. Cairo Univ., 77 ( C): 1-17.

Rodriguez Vaquero L. R. ;Serrvalle T. ;Manca de Nadra M. C. S. and Trasser de Saad A. M. (2010): Antioxidant Capacity and antimicrobial activity of phenolic compound from argentinean herbsinfusions, Food Control 21, 779-785.

Saad B.; Yong Y.S.; Mohd A.N. ; Noorhassni H.; Abdussalam S.M.A.; Muhammad I.S. ; Saida F.S.; Khariuddin M.T.; Kamarudzaman A. (2007): Determination of synthetic phenolic antioxidant in food items using reversed-phase HPLC . Food Chem. $105,389-394$.
Saeed D.; Morad M.; Zahra E.; Seyed M. (2013): Pomegranate seed: A comparative study on biochemical composition and oil physicochemical characteristics. International Journal of Advanced Biological and Biomedical Research. 4, 351-363.

Sassano G.; Sanderson P.; Frank J.; Groot P.; Straalen V.L. and Bassaganya-Rierac J. (2009): Analysis of pomegranate seed oil for the presence of jacaric acid. Journal of Science Food and Agriculture, 89: 1046-1052.

Shan B. Cai YZ, Brooks J.D and Corke H. (2007): The in Vitro antibacterial activity of dairy spice and medicine herb extracts. Int. J. Food Microbiol. 117: 112-119.

Singh G.; Kapoor I.P.S.; Singh P.; Heluani C. S.; Iampasona M.P. and Catalan C. A. N. (2008): Chemistry ' antioxidant and antimicrobial investigation on essential oil and oleoresins of Zingiber officinale . Food Chem.Toxicol.45，32903302.

Smith-Palmer A.; Stewart J. and Fyfe L. (2001): The potential application of plant essential oils as natural food preservatives in soft cheese. Food Microbial .18, 463-470.

Susana Nelson (1995): Food analysis fat characterization (Oscar,A. pike), chapter 14, second edition .

Ultee A.; Bennik M.H. and Moezelaar R. (2002): The phenolic hydroxyl group of carvacrol is essential for action against the food- borne pathogen Bacillus cereus . Applied Enironmental Microbiology . 68 , 1561- 1568 .

Wenjiao F., C.; Yaunchuan S.; Junxiu and Yonkui Z. (2011): Effects of tea polyphenol on quality and shelf life of pork sausages. J. Food Sci .Technol. 51: 191-195.

\section{تأثير زيت بذور الرمان على بعض الاحياء المجهرية المسببة لتلف الغذاء ودورة فى اطالة مدة تخزين القشدة .

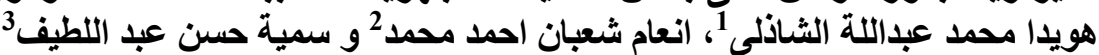

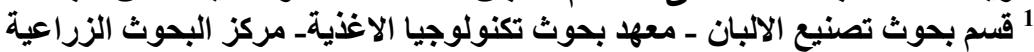

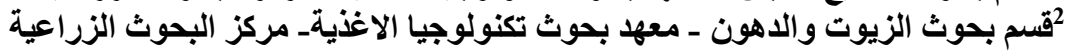

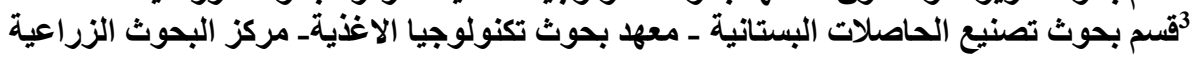

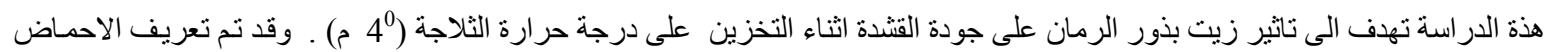

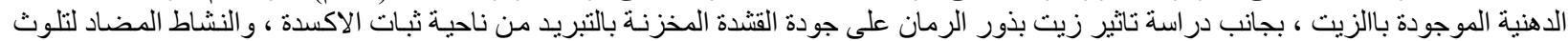

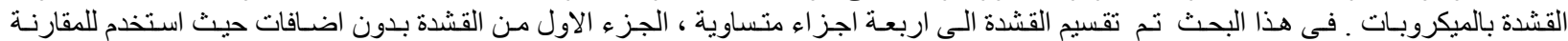

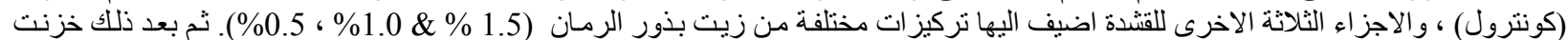

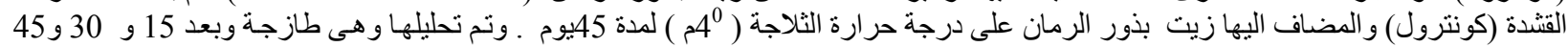

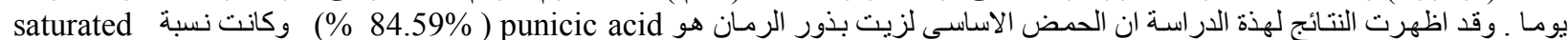

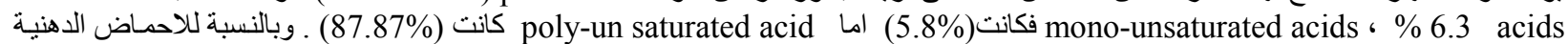

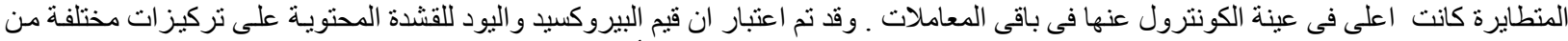

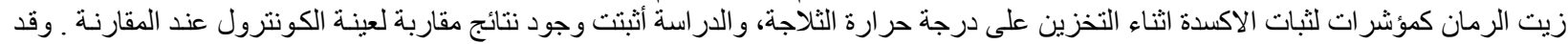

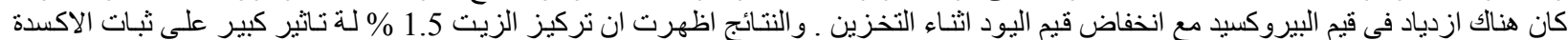

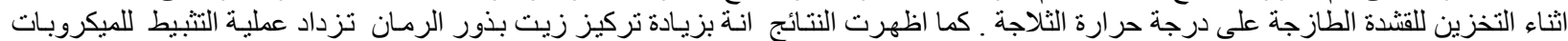

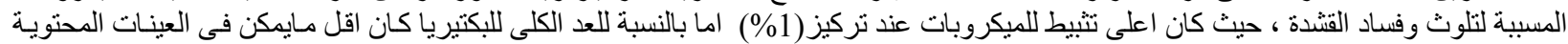

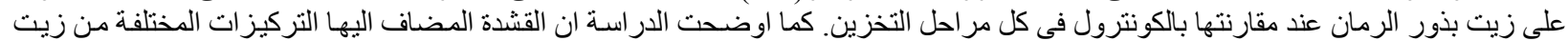

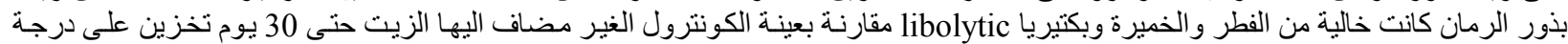

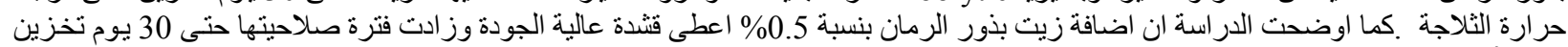

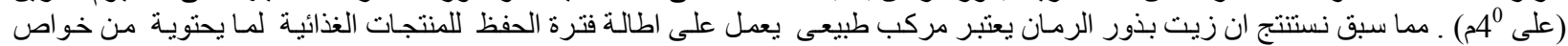

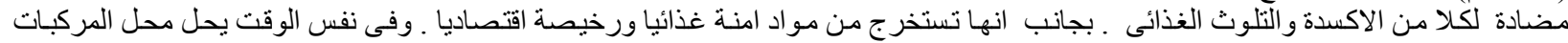

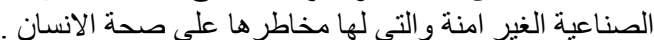

